\title{
Experimental Studies on the Changes in Resistivity and Its Anisotropy Using Electrical Resistivity Tomography
}

\author{
Tao Zhu, Jian-Guo Zhou, and Jin-Qi Hao \\ Institute of Geophysics, China Earthquake Administration, Beijing 100081, China \\ Correspondence should be addressed to Tao Zhu, zxl_tao@yahoo.com.cn
}

Received 10 March 2011; Revised 10 July 2011; Accepted 8 August 2011

Academic Editor: Sabatino Piscitelli

Copyright () 2012 Tao Zhu et al. This is an open access article distributed under the Creative Commons Attribution License, which permits unrestricted use, distribution, and reproduction in any medium, provided the original work is properly cited.

Three measuring lines were arranged on one of free planes of magnetite cuboid samples. Apparent resistivity data were acquired by MIR-2007 resistivity meter when samples were under uniaxial compression of servocontrol YAW-5000F loadingmachine in laboratory. Then we constructed the residual resistivity images using electrical resistivity tomography (ERT) and plotted the diagrams of apparent resistivity anisotropy coefficient (ARAC) $\lambda^{*}$ and the included angle $\alpha$ between the major axis of apparent resistivity anisotropy ellipse and the axis of load with pressure and effective depth. Our results show that with increasing pressure, resistivity and the decreased (D region) and increased (I region) resistivity regions have complex behaviors, but when pressure is higher than a certain value, the average resistivity decrease and the area of $\mathrm{D}$ region expand gradually in all time with the increase of pressure, which may be significant to the monitoring and prediction of earthquake, volcanic activities, and large-scale geologic motions. The effects of pressure on $\lambda^{*}$ and $\alpha$ are not very outstanding for dry magnetite samples.

\section{Introduction}

The striking changes in electrical resistivity and its anisotropy were widely observed before earthquake, mine earthquake, volcanic activities, and geologic motions [1-12]. In order to address the change characteristics of resistivity and its anisotropy, many investigators conducted a plenty of experiments on rock samples under compression and during fracture, shear, and frictional sliding in lab [13-25] and theoretic studies [26-30]. Experimental results reported by Brace et al. [13] and Brace and Orange [14-16] in lab showed that striking changes in electrical resistivity were observed for a variety of igneous and sedimentary crystalline rocks when water-saturated crystalline rocks were stressed to fracture. Resistivity decreased by as much as an order of magnitude. Most of the change occurred at stresses above half the fracture stress. The electrical resistivity of hematite decreased gradually with increasing shock pressure to $440 \mathrm{~kb}$ and decreased discontinuously to less than $1 \Omega \mathrm{cm}$ from several tens of $\Omega \mathrm{cm}$ at pressure of $440-520 \mathrm{~kb}$ [18], and that of a saturated granite during frictional sliding showed clear variations premonitory to the occurrence of stick-slip: resistivity decreased by a few percent with increasing shear stress; the minimum coincided with a sudden release of shear stress of a few bars, accompanied by an immediate return of resistivity [17]. Morrow and Brace [19] and Yamazaki [31,32] reported that the electrical resistance of tuffs changed very largely, particularly for small strains and could be applied to earthquake prediction [1]. Studies on the changes in resistivity anisotropy were conducted by Chen et al. [33] firstly in lab. They used the water-saturated crystalline rock samples and arranged three measuring lines parallel to, perpendicular to, and intersecting at the angle of $45^{\circ}$ with maximum principle stress axis on one of its free planes, and studied the relations between apparent resistivity anisotropy and pressure. Considering the effects of groundwater, An et al. studied the changes in resistivity and its anisotropy with pressure in the presence of feed water [34]. In order to recognize the expansion of fissure with stress, Chen et al. [22-25] studied the water-saturated granite samples and man-made samples under uniaxial compression, triaxial compression with low confining pressure, and frictional sliding. This previous work played very important role in recognizing and understanding the change behaviors of resistivity and its anisotropy with pressure, but they had to analyze the curves of resistivity and its anisotropy with pressure because of only a few electrodes 


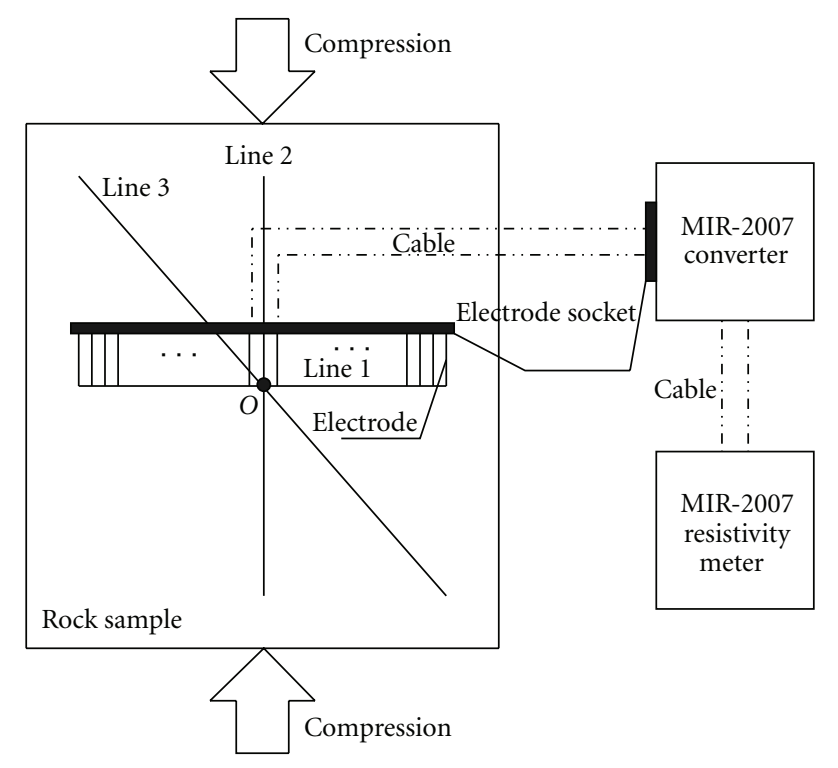

FIGURE 1: Sketch of test system.

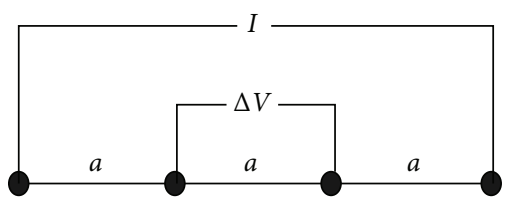

FIgURE 2: Sketch of Wenner- $\alpha$ array. $I$ indicates the intensity of current between two current electrodes $A$ and $B . \Delta V$ indicates the potential difference between two potential electrodes $M$ and $N$.

designed on one measuring line. In order to study the changes in resistivity and its anisotropy with pressure, we use MIR-2007 resistivity meter to acquire apparent resistivity data of dry magnetite samples in lab. In resistivity measurements, 37-120 electrodes and 12-30 " $n$ " factors [35] and Wenner- $\alpha$ array are used, and 210-1205 apparent resistivity measurements are acquired. We construct the resistivity images at each pressure value using ERT and plot the diagrams of $\lambda^{*}$ and $\alpha$ at each effective depth. Then the changes in resistivity and its image and anisotropy with pressure and depth are studied. We find that when the pressure is higher than a certain pressure, average resistivity will decrease, and the area of D region will expand gradually, and most of $\lambda^{*}$ and $\alpha$ change slightly with the increase of pressure.

\section{Experiments}

2.1. Samples. Two cuboid magnetite samples used in this study were collected in Yinan, Shandong province, China. Physical properties and geometric dimensions of specimens were listed in Table 1.

They mainly consist of magnetite (larger than 60\%), which leads to their good conductivity; so it is possible to conduct resistivity measurements easily. Their compression planes are the plane of $31.8 \times 22.0 \mathrm{~cm}$ for sample YN1 and of $29.0 \times 26.0 \mathrm{~cm}$ for sample YN2 in dimension.

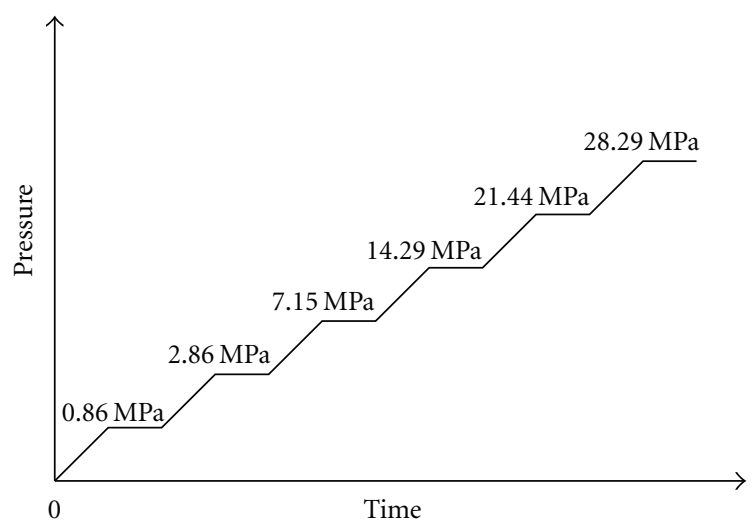

(a) Sample YN1

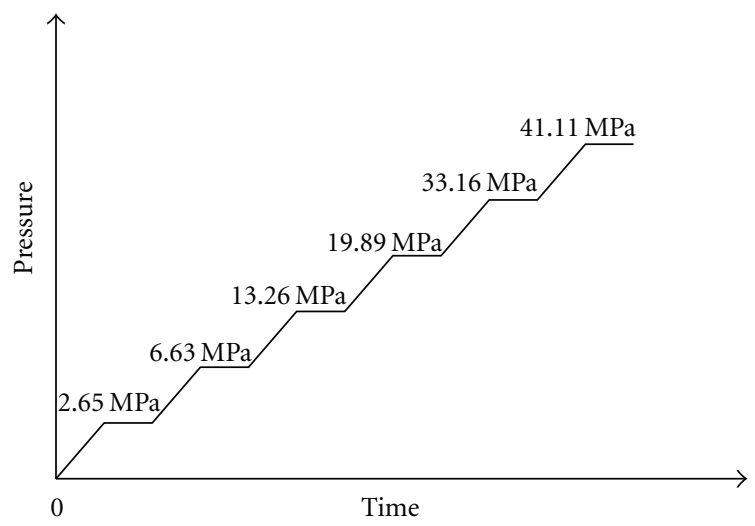

(b) Sample YN2

FIgURE 3: The loading curves of samples.

2.2. Experimental System. The experimental system used is shown in Figure 1. The uniaxial servocontrol YAW-5000F loading machine (http://shijin.shuoyi.com/shtml/shijin/product/57fd78bf28f0244d.html) manufactured by Jinnan Shijin Group Co. Ltd. was used for axial load. Three measuring lines are arranged on one of free planes. Line 1 and 2 are perpendicular and parallel to the axis of load, and Line 3 intersects this axis at the angle of $45^{\circ}$ (Figure 1). Three measuring lines all intersect at the point $O$ which almost locates the center of the free plane. Copper wires spot welded on the free planes are used as electrodes of resistivity measurements. The parameters of measuring lines of two samples are listed in Table 2. MIR-2007 resistivity meter used in this experiment was specially designed for resistivity measurement of rock sample in lab by Beijing Geological Instrument Factory (http://bjdzyqc.shuoyi.com/shtml/bjdzyqc/index.htm). The input impedance of the meter is about $4104 \mathrm{M} \Omega$, and its accuracy of potential measurement is about $0.15 \%$. Wenner$\alpha$ array (Figure 2) was used in data acquisition.

2.3. Loading Curves and Data Acquisition. The samples were compressed by uniaxial load (Figure 1). Their loading curves are shown in Figure 3. Resistivity measurements were conducted along measuring lines one by one when pressure increased to $0,0.86 \mathrm{MPa}, 2.86 \mathrm{MPa}, 7.15 \mathrm{MPa}, 14.29 \mathrm{MPa}$, $21.44 \mathrm{MPa}$, and $28.29 \mathrm{MPa}$ at uniform rate of $1.43 \times$ $10^{-2} \mathrm{MPa} / \mathrm{s}$ for sample YN1 and to $0,2.65 \mathrm{MPa}, 6.63 \mathrm{MPa}$, 

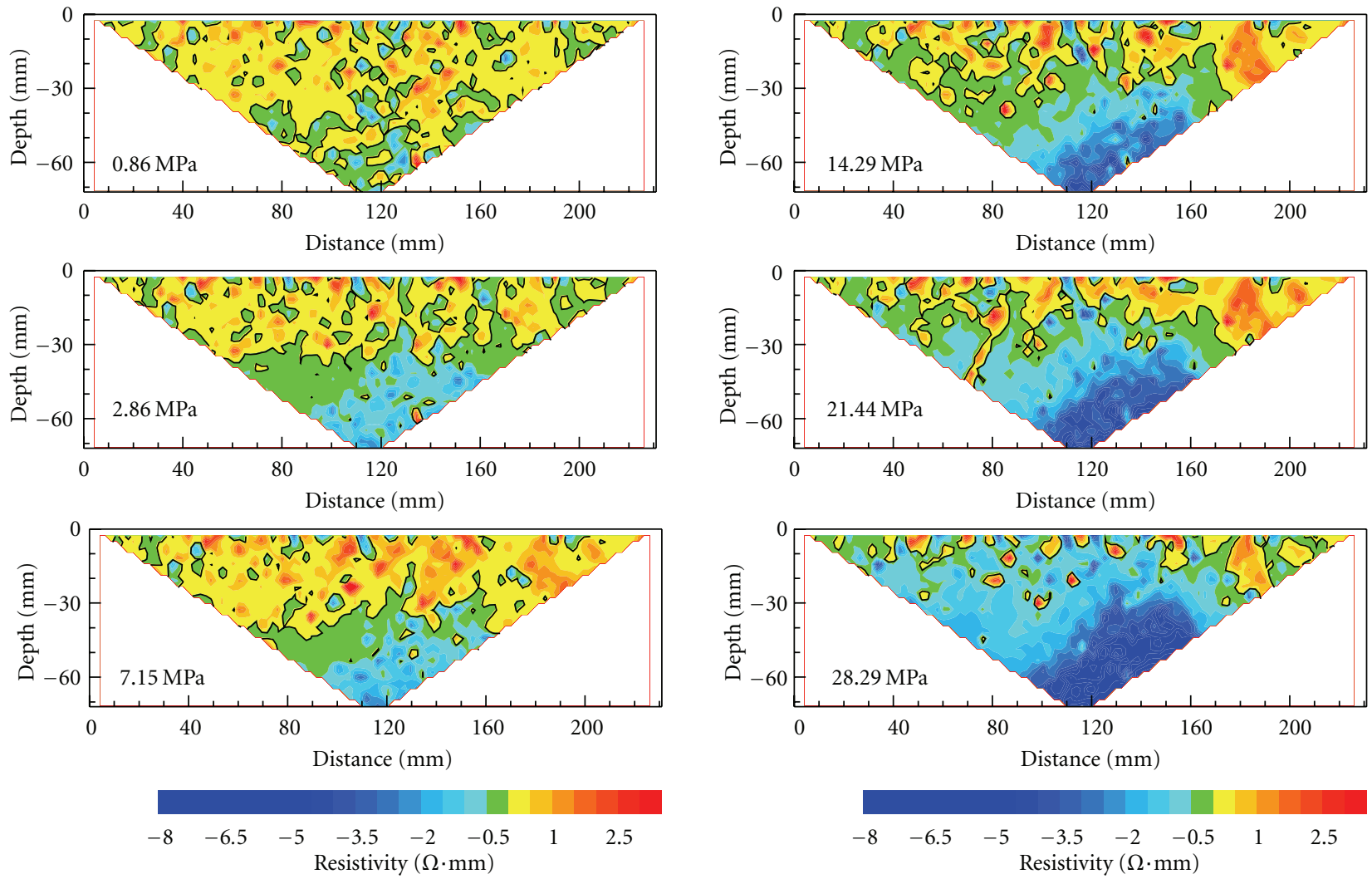

(a)
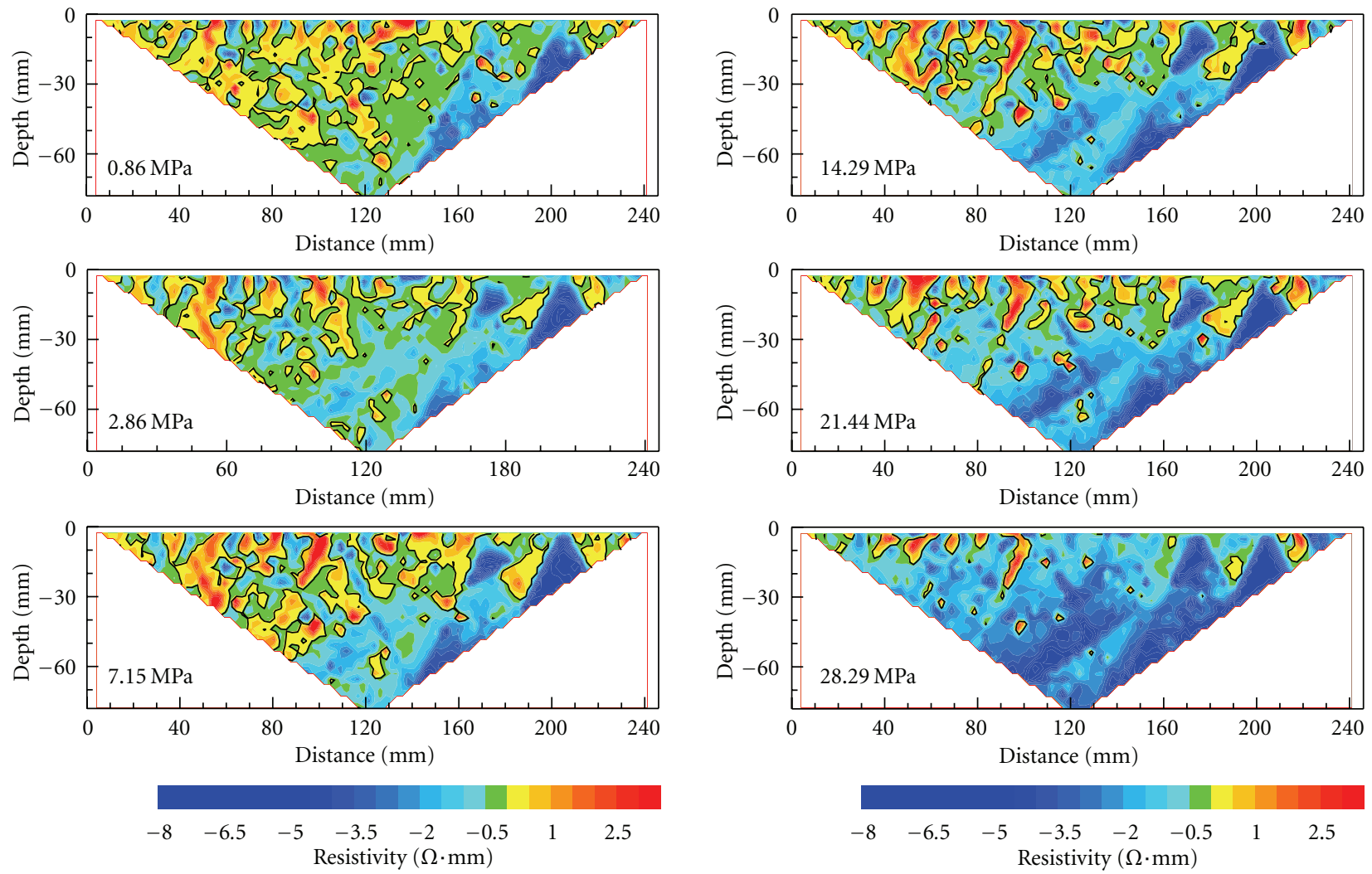

(b)

FIgURe 4: Continued. 

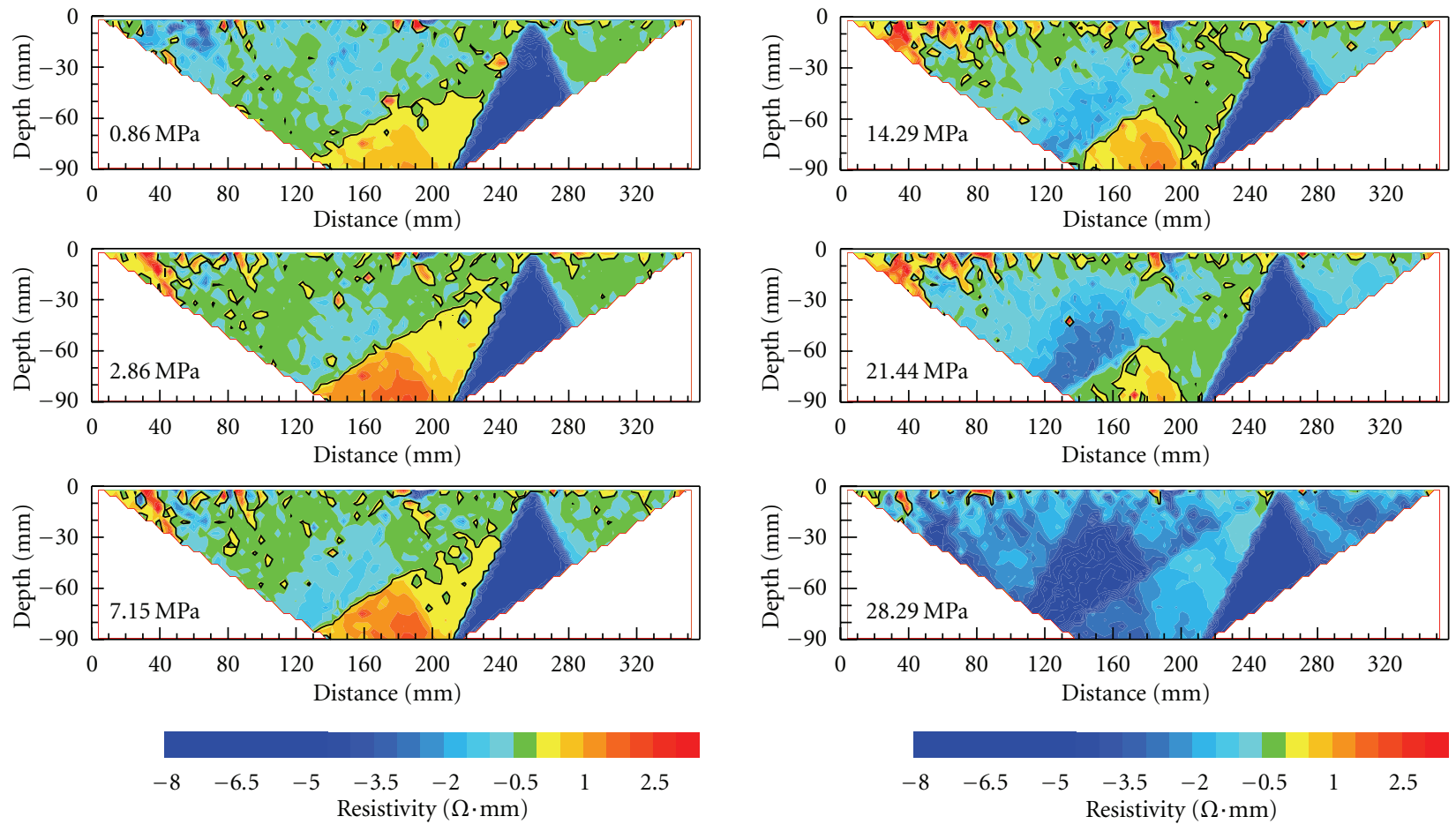

(c)

FIGURE 4: The residual resistivity images of sample YN1. (a) Line 1, (b) Line 2, and (c) Line 3.

TABLe 1: Physical properties and geometric dimensions of specimens.

\begin{tabular}{lccc}
\hline Sample no. & Density $\left(\mathrm{g} / \mathrm{cm}^{3}\right)$ & Dimension $(\mathrm{cm})$ & Modal analysis \\
\hline YN1 & 5.04 & $34.0 \times 31.8 \times 22.0$ & 64 Magnetite, 29 Quartz, 7 Feldspar \\
YN2 & 5.07 & $34.0 \times 29.0 \times 26.0$ & 68 Magnetite, 27 Quartz, 5 Feldspar \\
\hline
\end{tabular}

TABle 2: Parameters of measuring lines.

\begin{tabular}{lccc}
\hline ML & NE & SE & NF \\
\hline Line 1 & \multicolumn{2}{c}{ Sample YN1 } \\
Line 2 & 88 & $3 \mathrm{~mm}$ & 24 \\
Line 3 & 120 & $3 \mathrm{~mm}$ & 26 \\
\hline \multicolumn{5}{c}{ Sample YN2 } \\
\hline Line 1 & 37 & $5 \mathrm{~mm}$ & 30 \\
Line 2 & 52 & $5 \mathrm{~mm}$ & 12 \\
Line 3 & 66 & $5 \mathrm{~mm}$ & 17 \\
\hline
\end{tabular}

Note: ML, NE, SE, and NF indicate measuring line, number of electrode, spacing of electrode, and " $n$ " factors, respectively.

13.26 MPa, 19.89 MPa, 33.16 MPa, and 41.11 MPa at $2.65 \times$ $10^{-2} \mathrm{MPa} / \mathrm{s}$ for sample YN2 and remained constant at each value. It took about 3 hours for sample YN1 and 1.5 hours for sample YN2 for resistivity measurement at each pressure value. In the meantime, time-lapse strain was recorded. To our regret, the strain curves remained straight lines throughout the experiment. We thought that the pressure was not enough high to lead to the measurable deformation recorded by our strain gauge.

\section{Results and Analysis}

3.1. Residual Apparent Resistivity Image (RARI). Residual apparent resistivity values were calculated via

$$
\rho_{N R}=\rho_{N}-\rho_{0},
$$

where $\rho_{N R}$ and $\rho_{N}$ represent the residual and measured apparent resistivity value at the pressure value of $N \mathrm{MPa}$, and $\rho_{0}$ indicates the apparent resistivity measurement at zero pressure. $N$ takes $0.86 \mathrm{MPa}, 2.86 \mathrm{MPa}, 7.15 \mathrm{MPa}, 14.29 \mathrm{MPa}$, $21.44 \mathrm{MPa}$, and $28.29 \mathrm{MPa}$ for sample $\mathrm{YN} 1$ and $2.65 \mathrm{MPa}$, 6.63 MPa, 13.26 MPa, 19.89 MPa, 33.16 MPa, and 41.11 MPa for sample YN2.

As are shown in Figures 4 and 5, the RARIs along three measuring lines have different change behaviors with pressure when the pressure is smaller than $7.15 \mathrm{MPa}$ for sample YN1 (Figure 4) and 6.63 MPa for sample YN2 (Figure 5). Figure 4 indicates that the RARIs could be divided simply into D (blue to green zone) and I (yellow to red zone) region. 

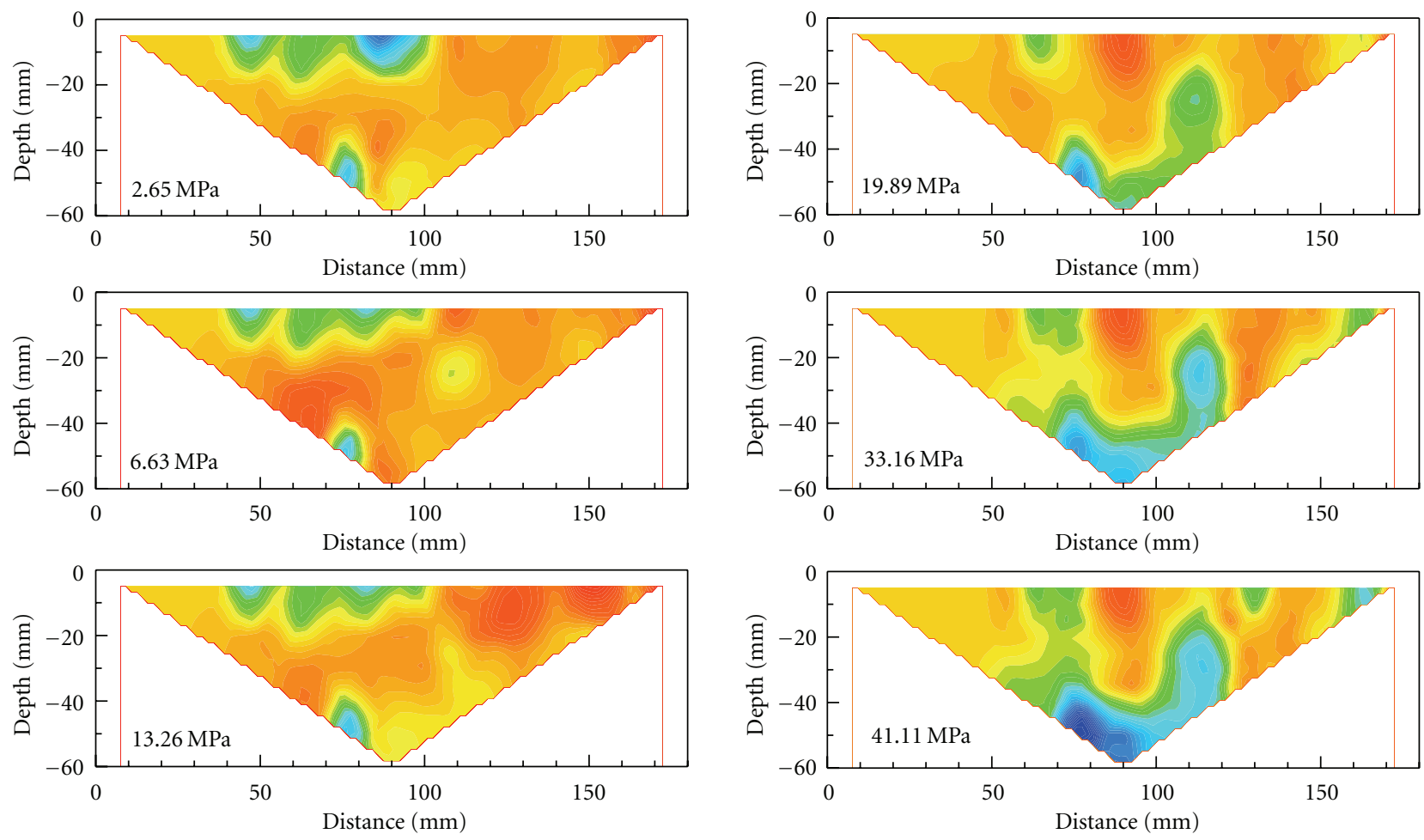

$-5-4-3-2-1 \quad 0 \quad 1 \quad 203045$

$-5-4-3-2-1 \quad 0 \quad 1 \quad 2 \quad 3 \quad 4 \quad 5$

Resistivity $(\Omega \cdot \mathrm{mm})$

(a)
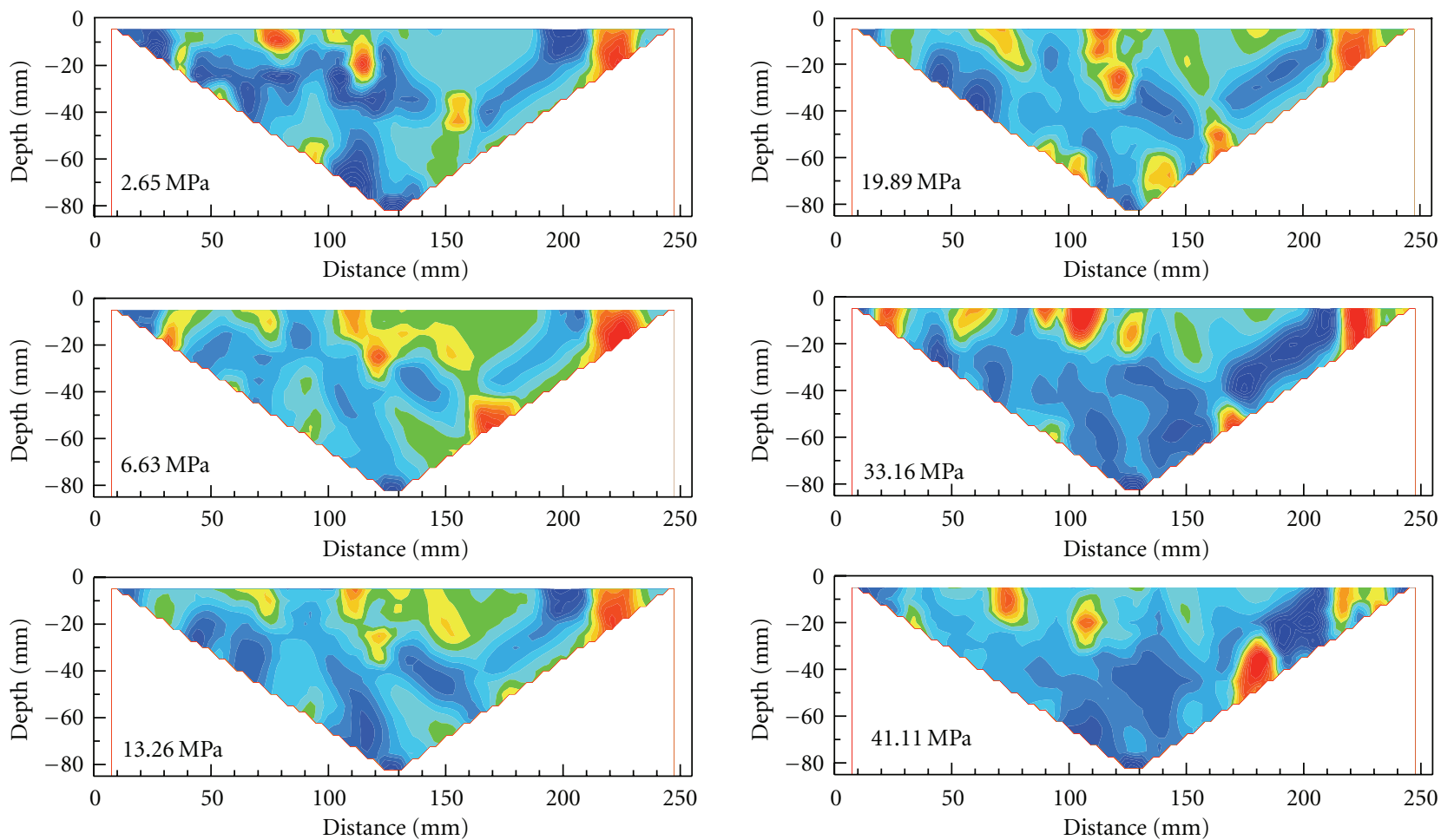

$-6-4.5-3-1.5 \quad 0 \quad 1.5 \quad 3 \quad 4.5$ Resistivity $(\Omega \cdot \mathrm{mm})$ Resistivity $(\Omega \cdot \mathrm{mm})$

(b)

FIgURe 5: Continued. 

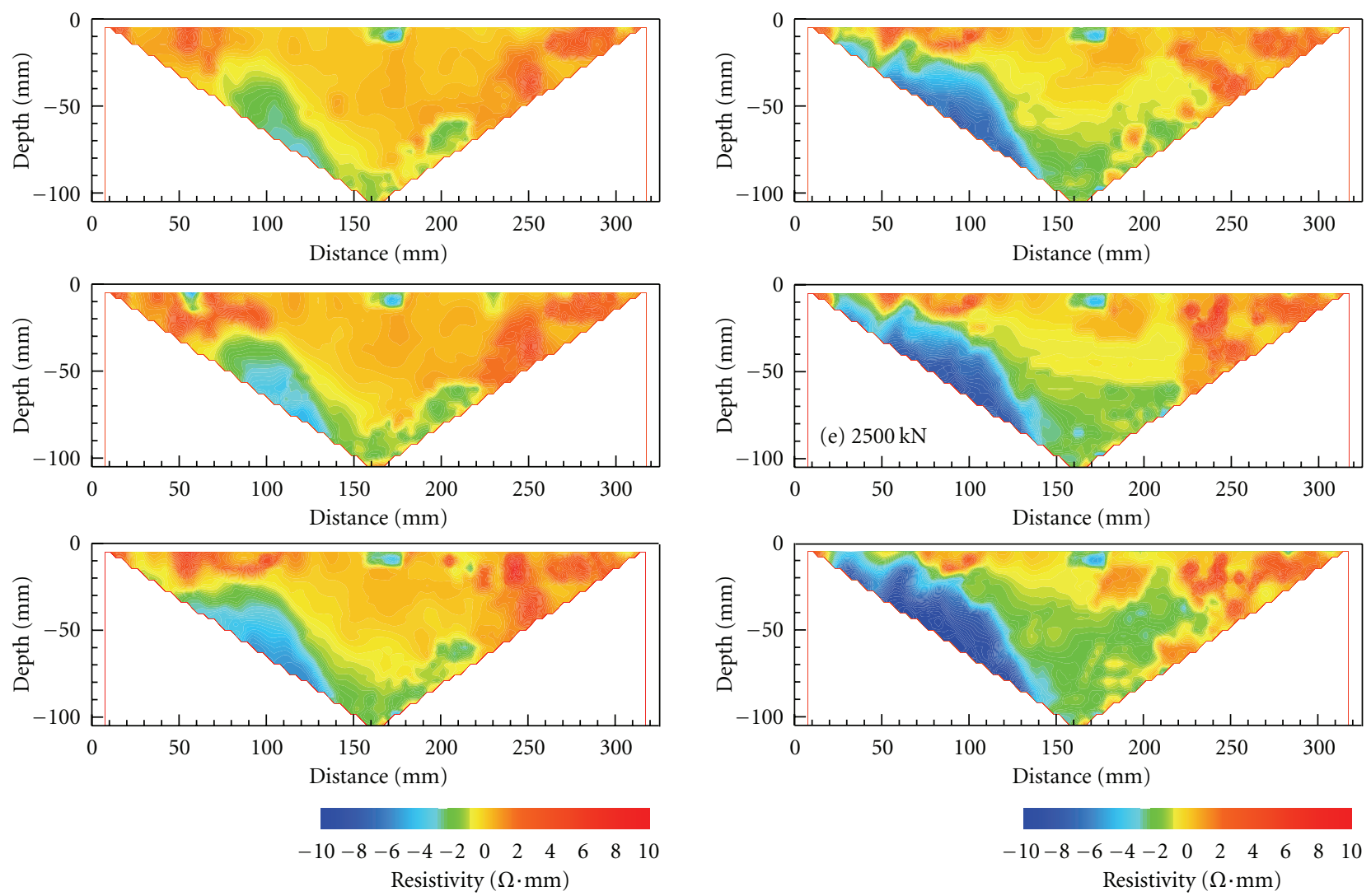

(c)

FIGURE 5: The residual resistivity images of sample YN2. (a) Line 1, (b) Line 2, and (c) Line 3.

With the increase of pressure, the average electrical resistivities of D region in Figure 4(a) increase (i.e., the average decreased magnitude becomes smaller) (compared the RARIs at $0.86 \mathrm{MPa}$ and $2.86 \mathrm{MPa}$ ) firstly and then decrease (i.e., the average decreased magnitude becomes larger), (compared the RARIs at $2.86 \mathrm{MPa}$ and $7.15 \mathrm{MPa}$ ), while those of I region in Figure 4(a) decrease firstly and then increase. The area of D region expands strikingly firstly and then almost remains constant, while that of I region reduces outstandingly firstly and then almost keeps constant. The electrical resistivities of D region in Figure 4(b) decrease in all time, and those of I region decrease firstly and then increase. The area of $\mathrm{D}$ region expands firstly and then reduces. The electrical resistivities of D and I region in Figure 4(c) both increase firstly and then decrease. The area of $\mathrm{D}$ region reduces firstly and then almost remains constant while that of I region increases firstly and then almost remains constant. With the increase of pressure from 2.65 MPa to $6.63 \mathrm{MPa}$, the electrical resistivities of D and I regions in Figures 5(a) and 5(b) all increase slightly. The area of D region expands slightly, and that of I region reduces slightly in Figure 5(a) while it is going in the opposite direction in Figure 5(b). The electrical resistivities of D and I region in Figure 5(c) both decrease slightly. The area of D region expands slightly while that of I region reduces slightly. When the pressure is larger than $7.15 \mathrm{MPa}$ for sample YN1 (Figure 4) and 6.63 MPa for sample YN2 (Figure 5), the electrical resistivities of D regions in Figures 4 and 5 all decrease gradually while those of I regions probably have complex change behaviors with the increase of pressure. For instance, they decrease firstly (As shown in the RARIs at $6.63 \mathrm{MPa}$ and $13.26 \mathrm{MPa}$ in Figure 5(a)), then increase (As shown in the RARIs at $13.26 \mathrm{MPa}$ and $19.89 \mathrm{MPa}$ in Figure 5(a)) and decrease gradually, at last (As shown in the RARIs at $19.89 \mathrm{MPa}, 33.16 \mathrm{MPa}$, and $41.11 \mathrm{MPa}$ in Figure 5(a)). However, the areas of D regions in Figures 4 and 5 all expand gradually and those of I regions are in opposite direction.

Our results show, as the previous investigators [14-19] reported, that electrical resistivities of rocks have complex behaviors with the increase of pressure. However, due to only two electrodes used in (volume) resistivity measurements, insufficient resistivity measurements could be used to construct resistivity image, and only the curves of resistivity versus pressure could be used to study the changes in resistivity with pressure in these previous studies. In this paper, 37-120 electrodes and 12-30 " $n$ " factors are used, and then 210-2205 resistivity measurements are acquired, which allow us to construct resistivity images easily we have the chance to study the changes in resistivity and its image with pressure in laboratory. Our results indicate that when pressure increases to a certain value, with the increase of pressure, the electrical 


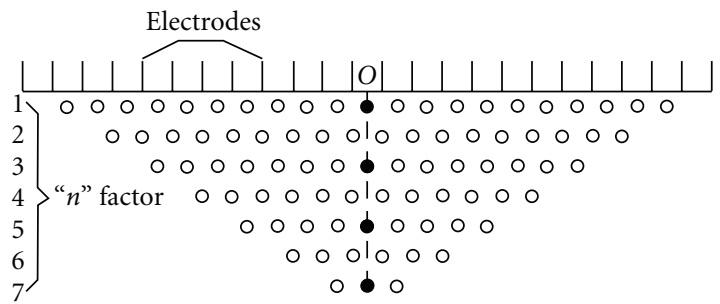

FIGURE 6: The illustration of extracting apparent resistivity set for Wenner- $\alpha$ array. In the studies on apparent resistivity anisotropy at point $O$, we need the apparent resistivity data arranged along the vertical dash line. According to the characteristics of Wenner- $\alpha$ array, the apparent resistivity measurements could be extracted every one " $n$ " factor. That is, the apparent resistivity measurements just corresponding to odd " $n$ " factors and on the vertical dash line will be extracted out. Black solid circles represent the extracted data.

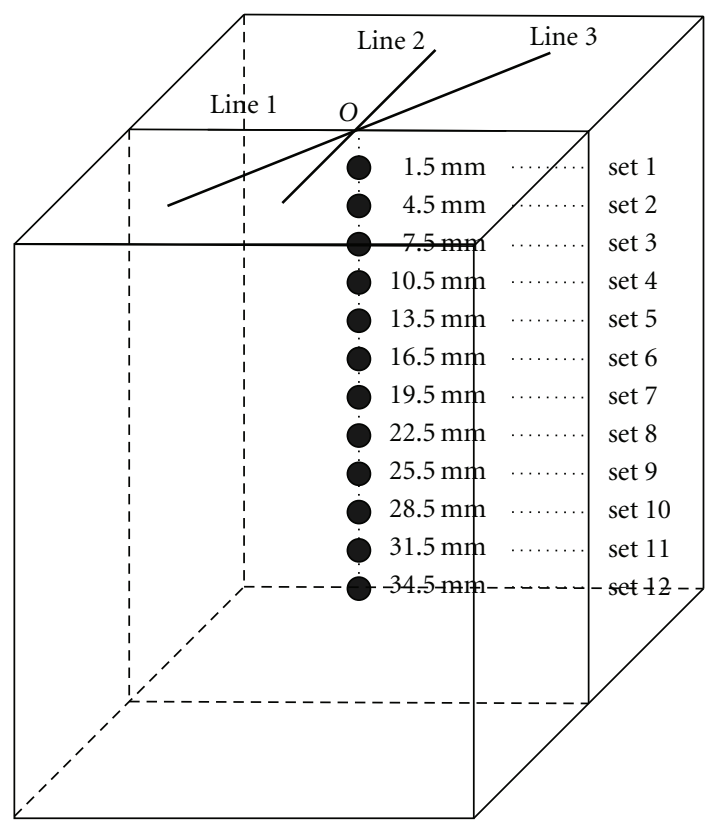

(a) Sample YN1

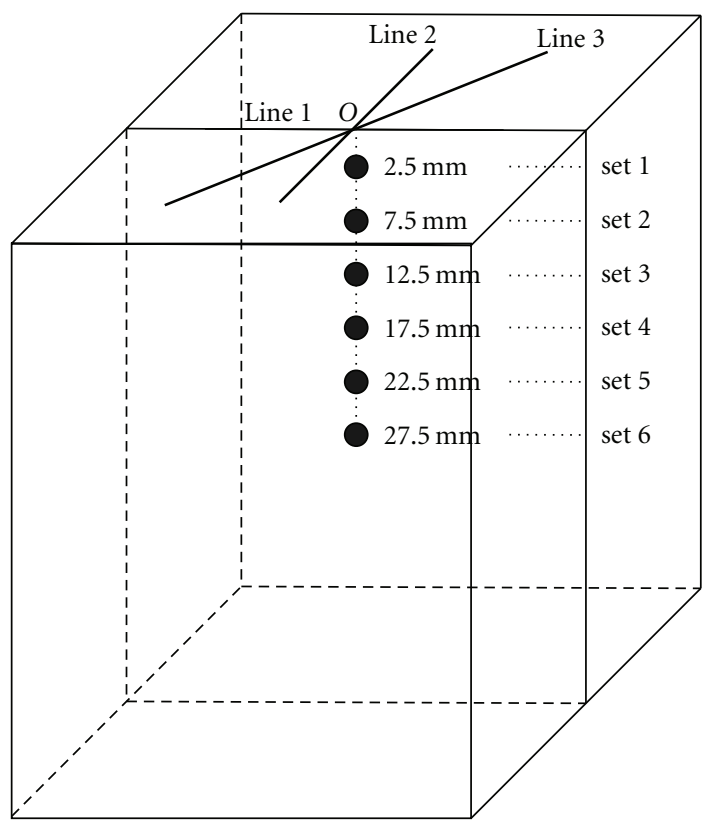

(b) Sample YN2

Figure 7: The diagram of apparent resistivity sets corresponding to effective depths. Because the effective depth of Wenner- $\alpha$ array was evaluated to be about 0.5 time of electrode spacing $[36,37]$, the 12 apparent resistivity sets were corresponding to the effective depths of about $1.5 \mathrm{~mm}, 4.5 \mathrm{~mm}, 7.5 \mathrm{~mm}, 10.5 \mathrm{~mm}, 13.5 \mathrm{~mm}, 16.5 \mathrm{~mm}, 19.5 \mathrm{~mm}, 22.5 \mathrm{~mm}, 25.5 \mathrm{~mm}, 28.5 \mathrm{~mm}, 31.5 \mathrm{~mm}$, and $34.5 \mathrm{~mm}$ for sample YN1, and 6 ones were corresponding to the effective depths of about $2.5 \mathrm{~mm}, 7.5 \mathrm{~mm}, 12.5 \mathrm{~mm}, 17.5 \mathrm{~mm}, 22.5 \mathrm{~mm}$, and $27.5 \mathrm{~mm}$ for sample YN2 according to Figure 6.

resistivities will decrease, and the area of $\mathrm{D}$ region will expand gradually in all time, which may be significant to the monitoring and prediction of earthquake, volcanic activities, and large-scale geologic motions.

\subsection{Apparent Resistivity Anisotropy}

3.2.1. Data Extraction. Studies on resistivity anisotropy require that resistivity measurements are conducted along at least two measuring lines arranged in different directions and that they must intersect at a point. For example, Mao et al. $[7,8]$ used the resistivity data measured along E-W and $\mathrm{N}-\mathrm{S}$ trending measuring lines in studying the changes in the degree of earth resistivity anisotropy during the course of earthquake preparation. Chen et al. [22-25] designed four measuring lines in studying the changes of apparent resistivity anisotropy in lab. In this paper, we arranged three measuring lines intersecting at point $O$ (Figure 1), which allowed us to study the changes in apparent resistivity anisotropy at point $O$ with pressure and depth. According to the used minimum " $n$ " factor and the characteristics of Wenner- $\alpha$ array in resistivity measurements, we could extract 12 apparent resistivity sets (Figure 6 illustrates how to extract the apparent resistivity set.) which are corresponding to 12 effective depths (Figure 7(a)) for sample YN1 and 6 apparent resistivity sets which are corresponding to 6 effective depths (Figure 7(b)) for sample YN2. It must be noted that one apparent resistivity set contains three apparent resistivity values. 


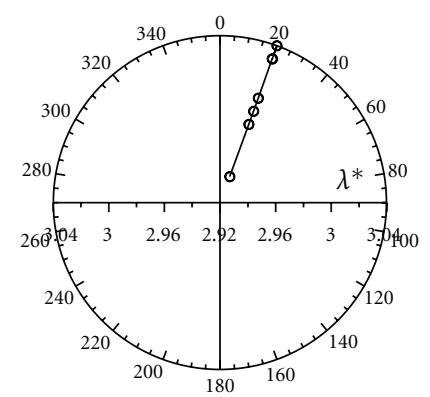

(a)

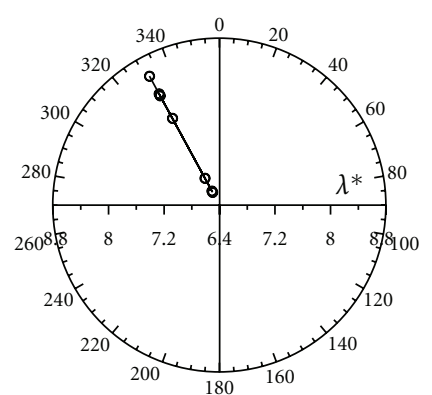

(e)

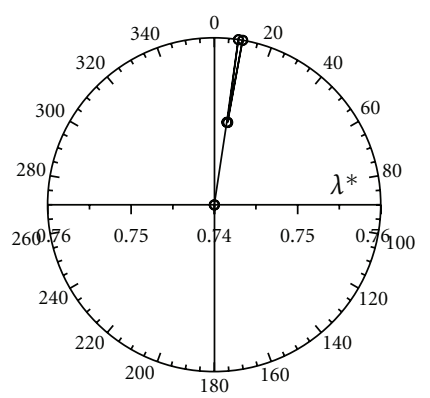

(i)

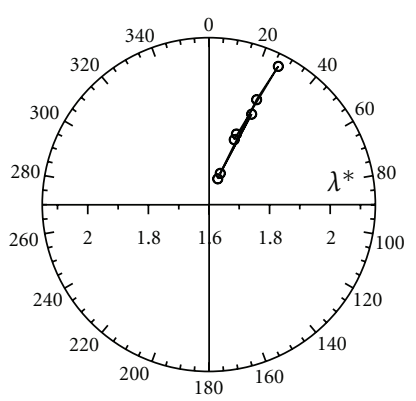

(b)

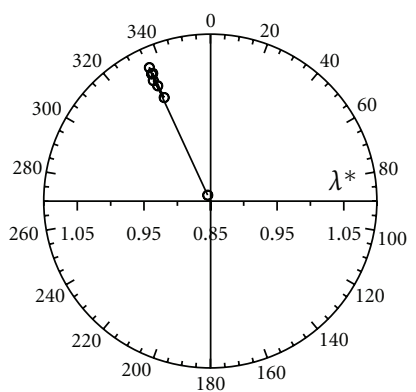

(f)

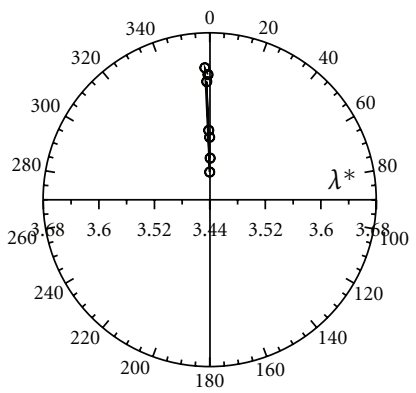

(j)

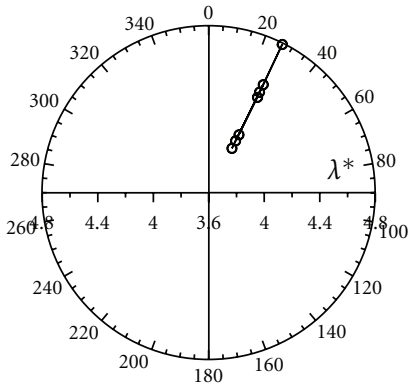

(c)

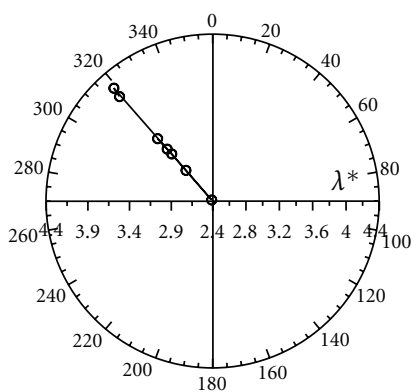

$(\mathrm{g})$

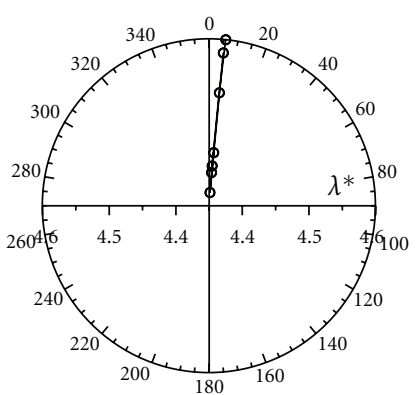

(k)

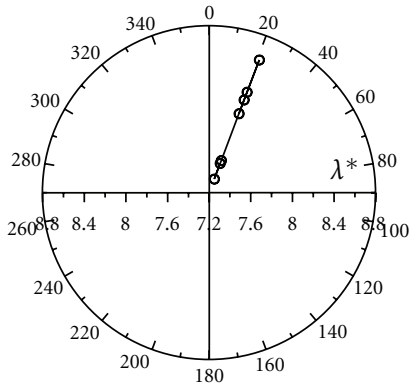

(d)

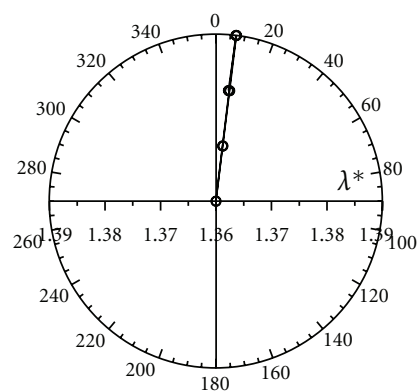

(h)

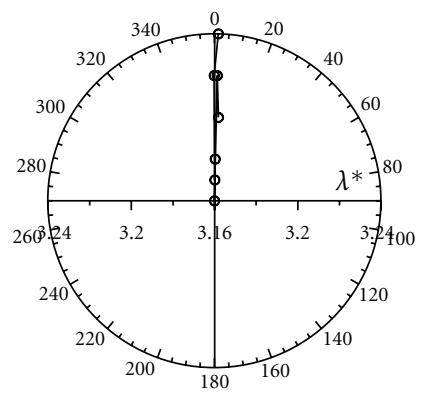

(1)

Figure 8: The diagrams of $\lambda^{*}$ and $\alpha$ with pressure for sample YN1. (a)-(1) represent the diagrams at the effective depths of $1.5 \mathrm{~mm}, 4.5 \mathrm{~mm}$, $7.5 \mathrm{~mm}, 10.5 \mathrm{~mm}, 13.5 \mathrm{~mm}, 16.5 \mathrm{~mm}, 19.5 \mathrm{~mm}, 22.5 \mathrm{~mm}, 25.5 \mathrm{~mm}, 28.5 \mathrm{~mm}, 31.5 \mathrm{~mm}$, and $34.5 \mathrm{~mm}$.

3.2.2. Apparent Resistivity Anisotropy Coefficient (ARAC). Chen et al. $[25,33]$ presented the formula to calculate ARAC $\lambda^{*}$

$$
\begin{gathered}
\lambda^{* 2}=\frac{2 \sqrt{m^{2}+Q^{2}}}{l-\sqrt{m^{2}+Q^{2}}}, \\
l=\rho_{s 1}^{-2}+\rho_{s 2}^{-2}, \\
m=\rho_{s 1}^{-2}-\rho_{s 2}^{-2}, \\
Q=2 \rho_{s 3}^{-2}-l,
\end{gathered}
$$

where $\rho_{s 1}, \rho_{s 2}$, and $\rho_{s 3}$ represent the apparent resistivities measured along three measuring lines perpendicular to, parallel to, and intersecting at the angle of $45^{\circ}$ with the axis of load.

Seen from the curves of $\lambda^{*}$ and $\alpha$ with pressure and depth for sample YN1 (Figure 8), the absolute differences between the minimum and the maximum $\lambda^{*}$ at $10.5 \mathrm{~mm}$ (Figure $8(\mathrm{~d})$ ), $13.5 \mathrm{~mm}$ (Figure $8(\mathrm{e})$ ), and $19.5 \mathrm{~mm}$
(Figure $8(\mathrm{~g})$ ) effective depths are about 1.6, 2.0, and 2.0, while those at the rest depths are all smaller than 0.5. The maximum change of $\alpha$, only about $7^{\circ}$, occurs at $4.5 \mathrm{~mm}$ depth. For sample YN2, the absolute difference between the minimum and the maximum $\lambda^{*}$ at $17.5 \mathrm{~mm}$ (Figure $9(\mathrm{~d})$ ) is about 4.0, while those at the rest depths are all smaller than 1.0. The maximum change of $\alpha$, about $80^{\circ}$, occurs at $22.5 \mathrm{~mm}$ depth, but those at the rest depths are all smaller than $5^{\circ}$. These results indicate that the effects of pressure on $\lambda^{*}$ and $\alpha$ are not very striking for dry magnetite samples.

\section{Discussions and Conclusions}

In the previous studies, the volume resistivity changes with pressure were actually studied [14-19]. It was impossible to construct resistivity image because of insufficient data; the curves of resistivity versus pressure were analyzed. In the present paper, resistivity measurements are conducted in the case of designed 37-120 electrodes and 12-30 " $n$ " factors, and 210-2205 resistivity values acquired are sufficient to 


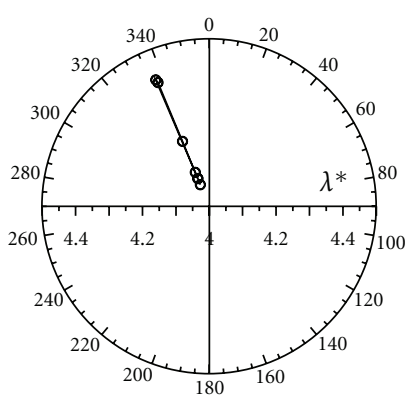

(a)

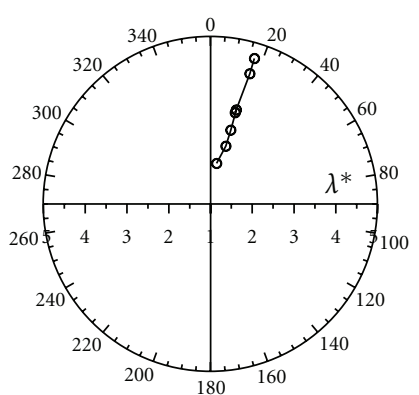

(d)

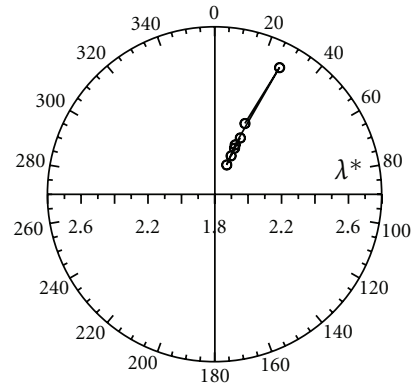

(b)

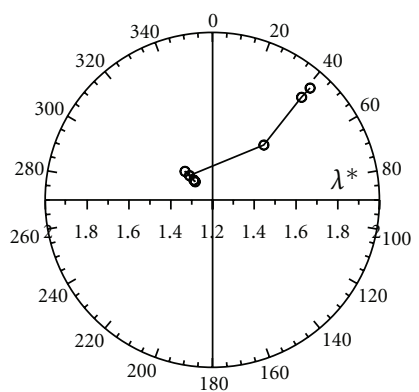

(e)

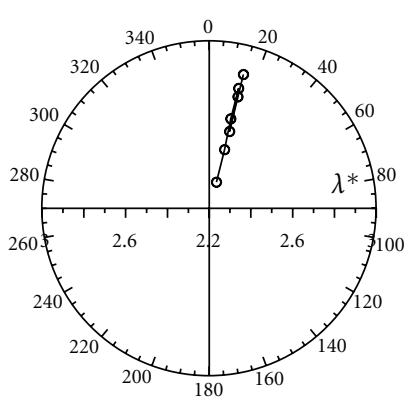

(c)

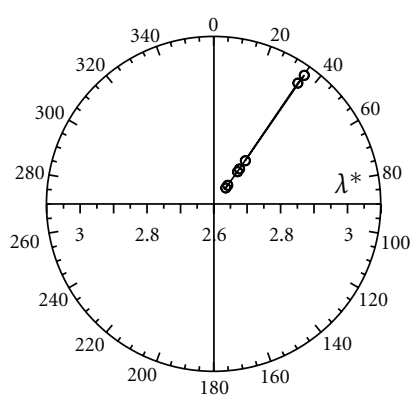

(f)

FIGURE 9: The diagrams of $\lambda^{*}$ and $\alpha$ with pressure for sample YN2. (a)-(f) represent the diagrams at the effective depths of $2.5 \mathrm{~mm}, 7.5 \mathrm{~mm}$, $12.5 \mathrm{~mm}, 17.5 \mathrm{~mm}, 22.5 \mathrm{~mm}$, and $27.5 \mathrm{~mm}$ effective depths.

allow us to use ERT to construct resistivity images which may contain much aplenty information than curves. Thus we can study the changes in not only resistivity but also in the areas of D and I region with pressure. Our results indicate that resistivity and the areas of $\mathrm{D}$ and I region have complex behaviors with increasing pressure when pressure is lower than a certain value such as $7.15 \mathrm{MPa}$ for sample YN1 and 6.63 MPa for sample YN2 in this paper, but when pressure is higher than this value, their behaviors become very simple with increasing pressure. For instance, when pressure is higher than $7.15 \mathrm{MPa}$ for sample YN1 and 6.63 MPa for sample YN2, the average resistivity of $\mathrm{D}$ region will decrease, and its area will expand gradually in all time with the increase of pressure. These changes were ever observed in situ by Feng et al. [9] prior to Tangshan ML 5.0 and 4.4, which probably indicate that our experimental results may be helpful and significant to the monitoring and prediction of earthquake, even for volcanic activities and large-scale geologic motions.

In the previous studies, the changes in apparent resistivity anisotropy at one or two depths with pressure were studied $[22-25,33,34]$ because of at most eight electrodes and two " $n$ " factors used in resistivity measurements, which lead to the difficulty in the studies on its changes with depth. In this paper, as described above, at least 78 electrodes and 24 " $n$ " factors for sample YN1 and 37 electrodes and 12 " $n$ " factors for sample YN2 (Table 2) and Wenner- $\alpha$ array were used in resistivity measurements, which allow us to calculate $\lambda^{*}$ and $\alpha$ at 6 or 12 effective depths (Figure 7) and give us the chance to study their changes with pressure at more depths. Our results indicate that $\lambda^{*}$ and $\alpha$ do not change outstandingly with the increase of pressure at a certain depth. However, the striking changes in apparent resistivity anisotropy were observed before earthquake $[7,8,38]$. We thought that we did not use water-saturated samples while the underground rocks are often in saturation because of the presence of rich groundwater. Therefore, water-saturated samples would be considered in our future study.

\section{Acknowledgments}

The authors thank two anonymous reviewers and the editor Sabatino Piscitelli for their constructive suggestions for this paper. This research was supported by the Special Project for the Fundamental R\&D of the Institute (DQJB07B09).

\section{References}

[1] Y. Yamazaki, "Electrical conductivity of strained rocks, 5, residual strains associated with large earthquakes as observed by a resistivity variometer," Bulletin of the Earthquake Research Institute, University of Tokyo, vol. 47, p. 99, 1969.

[2] D. Fitterman and T. Madden, "Resistivity observations during creep events at melendy Ranch, California," Journal of Geophysical Research, vol. 82, no. 33, pp. 5401-5408, 1977.

[3] W. Stopinski and R. Teisseyre, "Precursory rock resistivity variations related to mining tremors," Acta Geophysica Polonica, vol. 30, no. 4, pp. 293-320, 1982.

[4] D. B. Jackson, J. Kauahikaua, and C. J. Zablocki, "Resistivity monitoring of an active volcano using the controlled- source electromagnetic technique: Kilauea, Hawaii," Journal of Geophysical Research, vol. 90, no. 14, pp. 12-555, 1985.

[5] J. R. Kayal and B. Banerjee, "Anomalous behaviour of precursor resistivity in Shillong area, Northeast India," Geophysical Journal, vol. 94, no. 1, pp. 97-103, 1988. 
[6] T. Yukutake, T. Yoshino, H. Utada, H. Watanabe, Y. Hamano, and T. Shimomura, "Changes in the electrical resistivity of the central cone, Miharayama, of Oshima Volcano observed by a direct current method," Journal of Geomagnetism \& Geoelectricity, vol. 42, no. 3, pp. 151-169, 1990.

[7] T. Mao, T. Wang, J. Yao, J. Lu, and H. Zhang, "The variations of the degree of ground resistivity anisotropy during the tangshan earthquake," Acta Seismologica Sinica, vol. 8, no. 4, pp. 621-627, 1995.

[8] T. Mao, G. Xu, S. Fan, M. Zhao, and J. Sun, "Dynamic evolution patterns of the degree of ground resistivity anisotropy and the seismogenic process," Acta Seismologica Sinica, vol. 12, no. 2, pp. 199-206, 1999.

[9] R. Feng, J. Hao, and J. Zhou, "Resistivity tomography in earthquake monitoring," Chinese Journal of Geophysics, vol. 44, no. 6, pp. 819-830, 2001.

[10] Z. Feng, J. Yang, W. Mei, J. Geng, X. Wang, and Y. Liu, "Preliminary study on characteristics of seismic precursor of earth resistivity anisotropy degree in east China," Acta Seismologica Sinica, vol. 17, no. 2, pp. 244-250, 2004.

[11] H. Utada, "Interpretation of time changes in the apparent resistivity observed prior to the 1986 eruption of IzuOshima volcano, Japan," Journal of Volcanology and Geothermal Research, vol. 126, no. 1-2, pp. 97-107, 2003.

[12] J. An, P. Zhou, M. Ma, F. Chen, Y. Dong, and P. Zhong, "Experiments on exploring and monitoring landslip-mass using geoelectric resistivity observations," Acta Seismologica Sinica, vol. 21, no. 3, pp. 258-266, 2008.

[13] W. F. Brace, A. S. Orange, and T. M. Madden, "The effect of pressure on the electrical resistivity of water-saturated crystalline rocks," Journal of Geophysical Research, vol. 70, no. 22, pp. 5669-5678, 1965.

[14] W. F. Brace and A. S. Orange, "Electrical resistivity changes in saturated rock under stress," Science, vol. 153, no. 3743, pp. 1525-1526, 1966.

[15] W. F. Brace and A. S. Orange, "Electrical resistivity changes in saturated rocks during fracture and frictional sliding," Journal of Geophysical Research, vol. 73, no. 4, pp. 1433-1444, 1968.

[16] W. F. Brace and A. S. Orange, "Further studies of the effects of pressure on electrical resistivity of rocks," Journal of Geophysical Research, vol. 73, no. 16, pp. 5407-5420, 1968.

[17] C. Y. Wang, R. E. Goodman, P. N. Sundaram, and H. F. Morrison, "Electrical resistivity of granite in frictional sliding: application to earthquake prediction," Geophysical Research Letters, vol. 2, no. 12, pp. 525-528, 1975.

[18] K. Kondo, T. Mashimo, and A. Sawaoka, "Electrical resistivity and phase transformation of hematite under shock compression," Journal of Geophysical Research, vol. 85, no. 2, pp. 977982, 1980.

[19] C. Morrow and W. F. Brace, "Electrical resistivity changes in tuffs due to stress," Journal of Geophysical Research, vol. 86, no. 4, pp. 2929-2934, 1981.

[20] C. Pearson, J. Murphy, and R. Hermes, "Acoustic and resistivity measurements on rock samples containing tetrahydrofuran hydrates: laboratory analogues to natural gas hydrate deposits," Journal of Geophysical Research, vol. 91, no. 14, pp. 14132-14138, 1986.

[21] K. Skagius and I. Neretnieks, "Diffusivity measurements and electrical resistivity measurements in rock samples under mechanical stress," Water Resources Research, vol. 22, no. 4, pp. 570-580, 1986.
[22] F. Chen, J. Xiu, J. An, C. Liao, and D. Chen, “Detecting rupture precursors and determining the main fracture spread direction of rock with dynamic rock resistivity change anisotropy," Acta Seismologica Sinica, vol. 13, no. 2, pp. 234-237, 2000.

[23] F. Chen, J. Xiu, J. An, C. Liao, and D. Chen, "Research on dependence of resistivity changing anisotropy on microcracks extending in rock with experiment," Acta Seismologica Sinica, vol. 13, no. 3, pp. 331-341, 2000.

[24] F. Chen, C. Liao, and J. An, "Directional characteristic of resistivity changes in rock of original resistivity anisotropy," Chinese Journal of Geophysics, vol. 46, no. 2, pp. 381-395, 2003.

[25] F. Chen, C. Liao, and J. An, "Amplitude and anisotropy of apparent resistivity change in big models during shear and frictional slipping," Chinese Journal of Geophysics, vol. 46, no. 5, pp. 954-965, 2003.

[26] D. Fitterman, "Theoretical resistivity variations along stressed strike-slip faults," Journal of Geophysical Research, vol. 81, no. 26, pp. 4909-4915, 1976.

[27] D. L. Johnson and H. J. Manning, "Theory of pressure dependent resistivity in crystalline rocks," Journal of Geophysical Research, vol. 91, no. 11, pp. 11611-11617, 1986.

[28] K. Teisseyre, "Anisotropy of electric resistivity related to crack process before fracturing," Acta Geophysica Polonica, vol. 37, no. 2, pp. 185-192, 1989.

[29] K. Teisseyre, "Simulation of anisotropic changes of resistivity in primarily anisotropic rocks under load," Acta Geophysica Polonica, vol. 41, no. 3, pp. 316-333, 1991.

[30] K. Teisseyre, "Modeling of crack induced resistivity changesapplications to earthquake studies," Publications Institute of Geophysics, Polish Academy of Sciences, Series A, vol. 24, no. 274, pp. 1-63, 1997.

[31] Y. Yamazaki, "Electrical conductivity of strained rocks, 1, Laboratory experiments on sedimentary rocks," Bulletin of the Earthquake Research Institute, University of Tokyo, vol. 43, p. 783, 1965.

[32] Y. Yamazaki, "Electrical conductivity of strained rocks, 2, Further experiments on sedimentary rocks," Bulletin of the Earthquake Research Institute, University of Tokyo, vol. 44, p. 1553, 1966.

[33] D. Chen, F. Chen, and L. Wang, "Studies on resistivity of rock samples under uniaxial pressure-anisotropy of resistivity," Acta Geophysica Sinica, vol. 26, pp. 784-792, 1983 (Chinese).

[34] J. An, J. Xiu, F. Chen, and D. Chen, "Anisotropy studies of rock resistivity changes under uniaxial pressure and water replenishment," Earthquake Research in China, vol. 12, no. 3, pp. 300-306, 1996 (Chinese).

[35] I. Diaferia, M. Barchi, M. Loddo, D. Schiavone, and A. Siniscalchi, "Detailed imaging of tectonic structures by multiscale Earth resistivity tomographies: the Colfiorito normal faults (central Italy)," Geophysical Research Letters, vol. 33, no. 9, Article ID L09305, 2006.

[36] A. Roy and A. Apparao, "Depth of investigation in direct current methods," Geophysics, vol. 36, no. 5, pp. 943-957, 1971.

[37] L. S. Edwards, "A modified pseudosection for resistivity and IP,” Geophysics, vol. 42, no. 5, pp. 1020-1036, 1977.

[38] F. Qian, Y. Zhao, and Y. Huang, "Calculation of the parameters of georesistivity anisotropy and case history of earthquake precursors," Acta Seismologica Sinica, vol. 9, no. 4, pp. 617-627, 1999. 

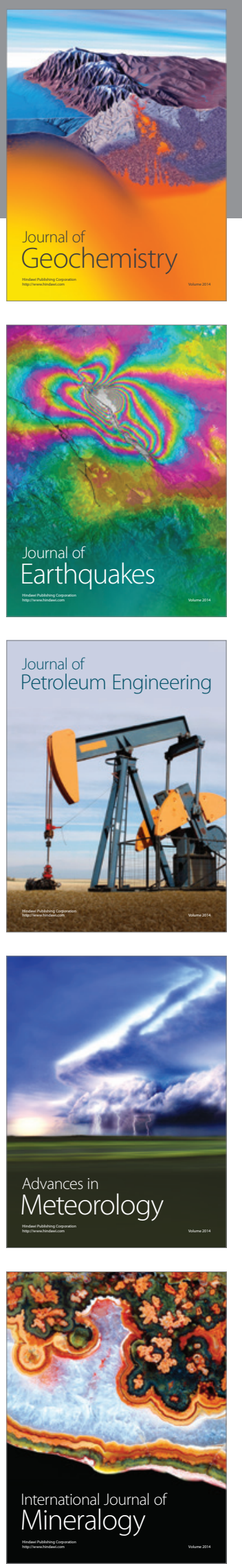
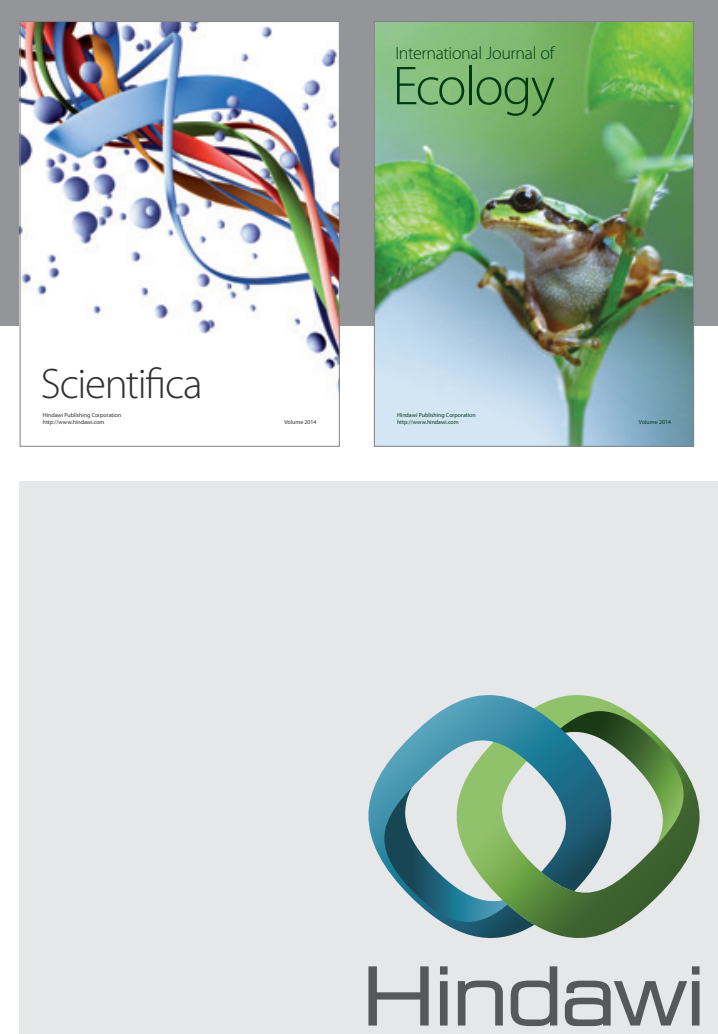

Submit your manuscripts at http://www.hindawi.com
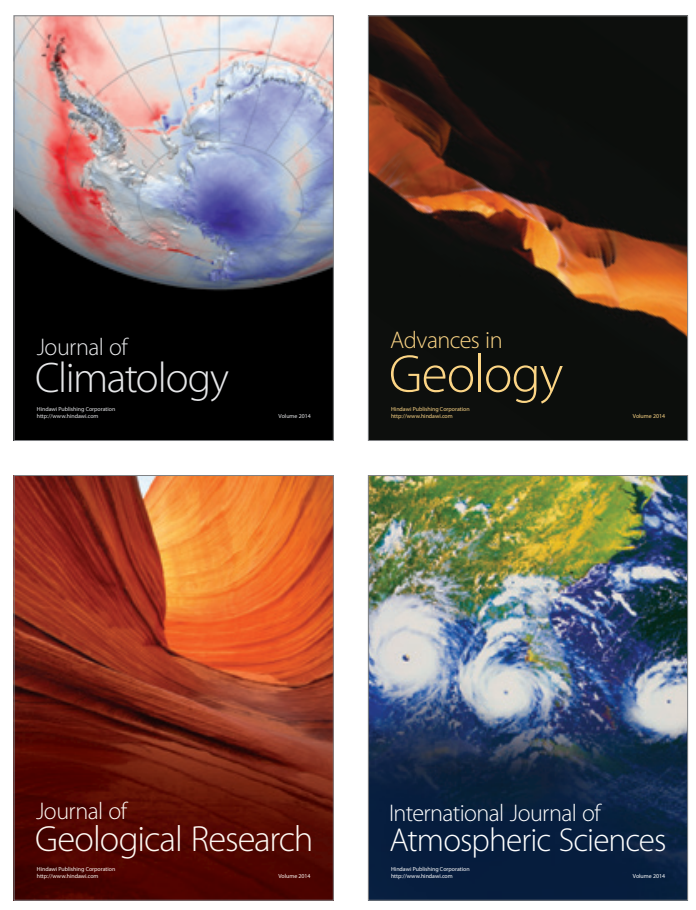
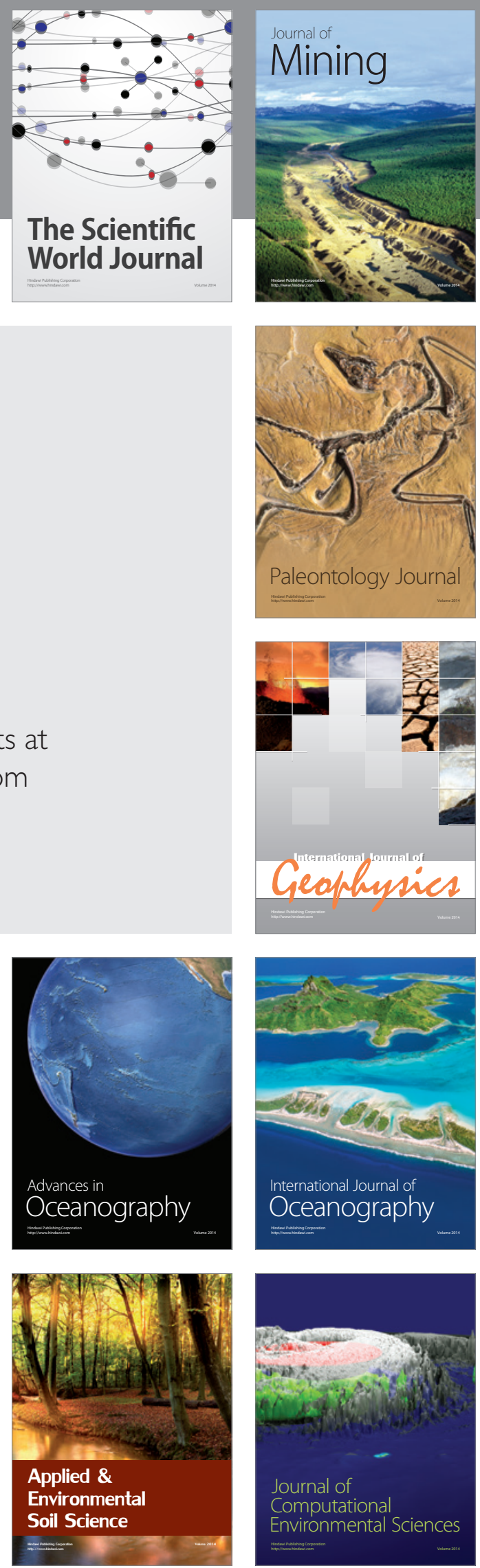